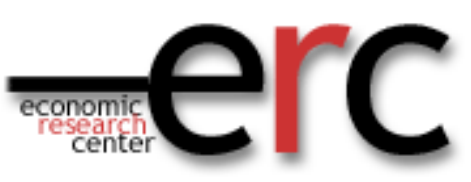

ERC Working Papers in Economics 16/02

February / 2016

\title{
Foreign Direct Investment as a Signal
}

\author{
Onur A. Koska \\ Department of Economics, Middle East Technical University, Ankara, Turkey \\ E-mail: koska@metu.edu.tr \\ Phone: + (90) 3122103046
}

Ngo Van Long

McGill University, Canada

E-mail: ngo.long@mcgill.ca

\section{Frank Stähler}

Department of Economics, University of Tübingen, Tübingen, Germany and Department of Economics, University of Adelaide, Adelaide, Australia and Center for Economic Studies, The Ifo Institute (CESifo), Munich, Germany

E-mail: frank.staehler@uni-tuebingen.de 


\title{
Foreign Direct Investment as a Signal
}

\author{
Onur A. Koska* Ngo Van Long ${ }^{\dagger}$ Frank Stähler ${ }^{\ddagger}$
}

\begin{abstract}
This paper models competition among multinational firms in an environment of firm heterogeneity, incomplete cost information and strategic interaction. In this context, FDI serves as a signal of productivity: when firms sort into exporters and multinationals, they also show whether they have low or high productivity. We show that the signaling effect of FDI increases the FDI incentive as firms would like to avoid sending a low productivity signal.
\end{abstract}

JEL-Classification: F23

Keywords: Foreign Direct Investment; Trade; Firm Heterogeneity; Incomplete Information; Signaling

${ }^{*}$ Corresponding Author: Middle East Technical University (METU), Department of Economics, Çankaya 06800, Ankara, Turkey. Tel: +(90) 312210 3046. Fax: +(90) 312210 7964. Email: koska@metu.edu.tr

${ }^{\dagger}$ McGill University, Canada. Email: ngo.long@mcgill.ca

${ }^{\ddagger}$ University of Tübingen and CESifo, Germany; University of Adelaide, Australia. Email: frank.staehler@uni-tuebingen.de 


\section{Introduction}

Foreign direct investment (FDI) has become a crucial driver of economic integration since the sales by foreign affiliates have outnumbered exports two decades ago. There is a considerably large literature devoted to the explanation of the existence of multinational firms and FDI. Starting with the knowledge-capital model by Markusen (1984), it has been shown that it is advantageous to operate multinational firms when firm-level scale economies, generated mostly by $\mathrm{R} \& \mathrm{D}$, are large, and plant-level scale economies are small (Horstmann and Markusen, 1992; and Markusen and Venables, 1998, 2000). Statistical evidence shows that multinationals intensively use professional and technical workers, and are well represented in capital-intensive and R\&D-intensive industries; see, for instance, Antràs and Yeaple (2013) for U.S. multinationals, Mayer and Ottaviano (2008) for French, German, Norwegian and Belgian multinationals, and Navaretti and Venables (2004) for French, German, Japanese, British and U.S. multinationals.

Multinationals' large R\&D investments and intensive use of professional and technical workers generate proprietary knowledge (patents, blueprints, technical know-how, or reputation), and are considered as an important source of firm heterogeneity. ${ }^{1}$ Extending Melitz's (2003) heterogeneous firm model, Helpman et al. (2004) show that FDI sales relative to exports are larger in industries with a more dispersed sales distribution, and that there is clear sorting by productivity: the most productive firms become multinational, whereas less productive firms export, and the least productive firms serve only local markets. ${ }^{2}$ This type of sorting is, by and large, supported by the results that emerge from the empirical literature on firm heterogeneity. ${ }^{3}$

\footnotetext{
${ }^{1}$ Unlike R\&D intensive industries, there seems to be little scope for heterogeneity in firms' technical know-how in advertising-intensive industries (Nocke and Yeaple, 2007).

${ }^{2}$ In theory, such types of sorting holds insofar as the profit function is supermodular in marginal costs (Mrázová and Neary, 2013).

${ }^{3}$ See, among others, Antràs and Yeaple (2013), Castellani and Giovannetti (2010), Arnold and Hussinger (2010), Aw and Lee (2008), Mayer and Ottaviano (2008), Castellani and Zanfei (2007), Tomiura (2007), Kimura and Kiyota (2006), Wagner (2006), and Girma et al. (2005; 2004). Also more productive firms in high $\mathrm{R} \& \mathrm{D}$ industries seem to prefer greenfield investment to a merger, or
} 
Both the knowledge-capital model and the heterogeneous firm model assume complete information. R\&D outcomes are, however, subject to uncertainty, and thus it seems plausible to suppose that in $\mathrm{R} \& \mathrm{D}$ intensive industries, firms do not know the productivity of their rivals. What are the implications of asymmetric information about productivity? Suppose that the most productive firms undertake FDI, as in Helpman et al. (2004). If a local firm observes the establishment of a foreign subsidiary, it may reasonably infer that it now faces a strong rival. Thus, the observation of a foreign firm's FDI will have an effect on domestic firm behavior. ${ }^{4}$ It is this effect we are interested in: what happens if FDI sends a message of high productivity in an environment of firm heterogeneity? We explore this by comparing the case where FDI is a signal with the benchmark case where output decisions must be made prior to the observation about FDI. ${ }^{5}$ We show that, for a given fixed FDI cost, both the probability of FDI and the expected industry output are greater under the signaling scenario than under the benchmark scenario. Thus, we have identified an important factor that contributes to the preponderance of FDI when firms are heterogeneous.

In our model, as in the literature on international trade with heterogeneous costs, firms self-select into different entry modes. We find that signaling enlarges the range of fixed FDI costs within which weak firms will choose exporting and strong firms will choose FDI. Furthermore, the threshold level of fixed FDI costs below which all types of firms will choose FDI is higher under the signaling case. This result reinforces our finding that the signaling environment is more conducive to FDI.

\footnotetext{
to a joint venture (Raff et al., 2012; Nocke and Yeaple, 2007). Moreover, since markets for knowledge are imperfect, firms decide to keep capital-intensive (research) activities within firm boundaries (Antràs, 2003).

${ }^{4}$ In concentrated (high R\&D) industries, firms generally have incomplete information about the costs of their foreign rivals (Collie and Hviid, 1993). A typical example is the micro-electronics industry where $R \& D$ investments/experience and some idiosyncratic factors determine firms' production costs. Incomplete cost information is also prevalent in the airline industry (Vives, 2002).

${ }^{5}$ The latter case is merely a theoretical benchmark that serves to isolate the signaling effect of FDI, while keeping the same underlying incomplete information structure of the model. In reality, FDI projects do not remain secret for long, and a substantial portion of strategic interactions occurs after the FDI takes place.
} 
The main contribution of this paper is to scrutinize both the strategic (signaling) effects of FDI and sorting by productivity in an environment of firm heterogeneity and incomplete cost information. Although empirical evidence suggests that information asymmetries crucially affect firms' cross-border investment strategies (e.g., see Lópes Duarte and García-Canal, 2004; García-Canal et al., 2002; and Shen and Reuer, 2005), only a few papers have explored the strategic effects of FDI in a setting of incomplete information. Long et al. (2011) consider a model with imperfect knowledge about rivals' production costs, but they rule out FDI in order to focus on export behavior and the role of R\&D under private information. In Katayama and Miyagiwa (2009), product quality is unknown and FDI is used to signal quality to consumers, whereas in Nastasi and Reverberi (2007), a firm uses FDI as a signaling device to deter market entry. In a model of asymmetric information about demand conditions, Moner-Colonques et al. (2007) show that firms may have an additional incentive to undertake FDI: to obtain more accurate demand information in the foreign market. There is, however, no study that takes on board both sorting and the signaling effects of FDI in an environment of firm heterogeneity.

Bagwell and Staiger (2003) consider a Cournot oligopoly in the foreign market which the Home firm supplies by either exporting or undertaking FDI. While the Home firm's cost is unknown to the foreign rivals, the costs of the foreign firms are common knowledge. The Home firm's location choice sends some information to the foreign rivals. In their model, the sorting by productivity thresholds are ruled out. ${ }^{6}$ They focus on a single firm's foreign market entry decision, and confine their analysis to the existence of multinationals. They show that if the asymmetric information is about the Home firm's productivity parameter, then a high-productivity Home firm will locate production in Foreign (where the wage is higher, $w^{*}>w$ ), in order to signal its high

\footnotetext{
${ }^{6}$ The intuitive concept of cost thresholds is typically applied to continuous random variables. Bagwell and Staiger (2003) assume the firm's cost type is a discrete random variable: either high or low. Their separating equilibrium is a sorting equilibrium but, of course, the threshold concept is more natural in the context of a continuous random variable.
} 
productivity. $^{7}$ If, however, the private information is about the domestic wage (high or low), then according to their model's set-up, choosing exporting will generate an incomplete cost information game, whereas locating production in the foreign country (FDI) will lead to competition under complete information. ${ }^{8}$

Our model is different. We do not restrict private information to the Home firm, and we do not rely on factor price differences across countries. Our model adds two features in the context of heterogeneous firm models: marginal production costs are private information, and FDI may serve as a signal. In particular, the main motivation is to find out how sorting by productivity is modified when FDI can serve as a signal in an environment of firm heterogeneity. We find that, when there is no possibility of signaling, under incomplete information the more efficient firms undertake FDI, whereas less efficient firms self-select into exporting, and the greater the degree of exante firm heterogeneity, the more likely we will observe a diversity of international business strategies. When signaling is possible, we find that the signaling effect of FDI makes FDI more likely, both in terms of the levels of fixed cost thresholds, and in terms of the size of the range of fixed investment costs. Comparing the signaling case with the non-signaling case, we find that the expected aggregate supply to each market is larger if FDI can serve as a signal of productivity. We also find that the signaling effect of FDI makes each firm achieve a bigger market share in the foreign market (compared to the non-signaling case).

\footnotetext{
${ }^{7}$ Curiously, if the wage in the domestic country is higher, their model would predict that only the less productive type would multinationalize, which is contrary to the evidence reported in e.g., footnote 3. Also, curiously, they assume that if the Home firm chooses FDI, then its export option is closed completely, even though there is no transport cost and the foreign wage is higher.

${ }^{8}$ In this case, the location choice amounts to the choice of information structure for the ensuing Cournot rivalry game, and Bagwell and Staiger (2003) show that there is no equilibrium in which the Home firm chooses FDI or exporting according to the (private information) domestic wage being low or high (Theorem 5). When they consider the case of linear demand, they focus on the case where there is no fixed FDI costs, and find that it is not possible to have an equilibrium such that the Home firm would choose FDI irrespective of the (private information) domestic wage being low or high. However, when assumptions are changed so that transport costs are positive and FDI involves a fixed cost, then some parameter values exist such that FDI is chosen regardless of the domestic wage being low or high (Theorem 11).
} 
The remainder of this paper is organized as follows. Section 2 introduces the model and considers the benchmark case of FDI under incomplete information, without signaling possibilities. Section 3 extends the model to the case where a firm's FDI decision signals its marginal cost. Section 4 compares the two cases to show how signaling affects the probability of FDI and the expected industry output. Section 5 concludes the paper. For readability, we have relegated the exposition of some computations to the Appendix.

\section{FDI under incomplete cost information: the non- signaling case}

Our model consists of two countries and two firms. Each firm has its headquarters in its own country. A firm must incur a fixed $\operatorname{cost} Z$ in order to be able to produce, and we assume that the size of this fixed $\operatorname{cost} Z$ is such that only one firm will have entered in each country. Also we assume that this fixed cost $Z$ is independent of the foreign entry mode (FDI or exporting; but FDI involves an additional fixed cost $F$ ). Thus $Z$ does not play any role in determining the foreign entry mode. The firm that is based in country $i$, denoted firm $i$, competes against the firm that is based in country $j$, denoted firm $j$, in both markets $i$ and $j, i \neq j$. Since FDI is capacity-building and thus a lasting commitment, we develop a model in which firms compete by quantities or capacities. ${ }^{9}$

Following the empirical evidence, to reflect the fact that multinational firms are more productive on average, we choose a set-up in which firms have a genuine interest to be of high productivity, and this is the reason why we employ the simplest model of strategic substitutes in the sense of Bulow et al. (1985). Thus, our model encompasses

\footnotetext{
${ }^{9}$ In a setting of complete cost information, the Cournot model is well-known to be strategically equivalent to a two-stage capacity-price game (Kreps and Scheinkman, 1983).
} 
the reciprocal dumping model of Brander and Krugman (1983), and the reciprocal FDI model of De Santis and Stähler (2004), along with two additional features: marginal production costs are private information, and FDI may serve as a signal. We defer, however, the signaling aspect of FDI until Section 4. In our model, marginal production costs, denoted $c$, are private information. After market entry (by paying $Z$ that is sunk), firms draw their costs from the uniform density distribution, with cumulative distribution function $\Phi(c)=(c-\alpha) /(\beta-\alpha)$, where $\beta$ and $\alpha$ are the upper and lower bounds, respectively. Thus, our model features both firm heterogeneity and the strategic aspect of private cost information. ${ }^{10}$

We denote by $q_{i}^{d}$ and $q_{i}^{f}$ the quantities that firm $i$ supplies to its own country's market and to the foreign market (either by exporting or by FDI). Therefore the total quantity supplied in country $i$ 's market is $Q_{i}=q_{i}^{d}+q_{j}^{f}$. We keep the demand side of the model as simple as possible, and assume that in each country the inverse demand function is given by $p_{k}=A-Q_{k},(k=i, j)$, as we assume that the two markets are segmented. ${ }^{11}$ The trade-off between serving a foreign market via exports or via FDI is as follows. If a firm decides for exports, there is a per-unit trade cost, denoted $t$, that the exporting firm has to cover; if a firm chooses FDI as the entry mode to the foreign market, it becomes a multinational and thus avoids the trade costs, although FDI requires additional fixed investment costs, denoted by $F$. In this respect, we follow the standard literature, featuring the well-known proximity-concentration trade-off. ${ }^{12}$ Both the per-unit trade cost and fixed investment costs are common knowledge. For the ease of exposition, we

\footnotetext{
${ }^{10}$ While the former is similar to Helpman et al. (2004), the latter is usually assumed away in the heterogeneous firm literature.

${ }^{11}$ Under complete information and symmetry, the assumption of segmented markets is innocuous because equilibrium prices are identical, so there is no reason for arbitrage. In our model, ex-ante symmetry does not imply ex post identical prices. If we allowed for arbitrage, we would have to take into account the probability that prices in the two markets differ by more than trade costs.

${ }^{12}$ In this respect, the model is very much in the style of Horstmann and Markusen (1992). The difference is that the two firms in our model can have different (constant) marginal costs, and so asymmetric equilibria (in terms of foreign market entry modes) are possible. In Horstmann and Markusen (1992), however, such equilibria can only occur if firms have increasing marginal costs.
} 
focus only on fixed FDI costs; an alternative interpretation would be that this is the difference between aggregate fixed costs of FDI and fixed costs of R\&D.

We are now ready to scrutinize the behavior of these two firms and the scope for FDI under incomplete information. In this section, we consider a one-stage game in which FDI cannot serve as a signal: both firms decide on exporting versus FDI at the same time as they decide on their outputs for the domestic and the foreign market. This is, then, a one-stage Bayesian game: when deciding on output levels, firms do not know each other's mode of supply to foreign markets, which is either by exporting or via FDI, nor do they know each other's marginal production costs. Each firm maximizes its expected profits and forms expectations on its rival's costs. These expectations must be rational: each firm knows which type of firms will self-select into which international business mode. We first show that (i) an interior solution (i.e., a separating equilibrium) exists such that different types will choose different strategies; and (ii) lower-cost types will choose FDI, whereas higher-cost types will choose exporting (as in the heterogeneous firm models) as to be confirmed in equilibrium. Corner solutions will be examined later.

Let $\Pi_{X}(c)$ and $\Pi_{F D I}(c)$ denote the expected profits of a firm of type $c$ when it chooses exporting and FDI, respectively. An interior solution requires that there exists a cost type $\delta \in[\alpha, \beta]$ that is indifferent between exporting and FDI such that $\Pi_{X}(c=\delta)=$ $\Pi_{F D I}(c=\delta)$. Consider first foreign firm $j$ that forms expectations about its rival $i$ 's cost in the domestic market $i$. This rival does not face any trade costs in serving its domestic market, and hence firm $j$ 's expectation of firm $i$ 's marginal cost of serving market $i$ is simply the expected value of $c$ :

$$
E_{j}\left(c_{i}^{d}\right)=\int_{\alpha}^{\beta} c \frac{1}{\beta-\alpha} d c=(\beta+\alpha) / 2
$$

Now consider domestic firm $i$ forming expectations on the cost of its rival $j$ in the 
domestic market. If firm $j$ serves country $i$ by exports, then it will have to bear a per-unit trade cost $t$. Given the uniform distribution, firm $i$ believes that firm $j$ will choose the export mode with probability $(\beta-\delta) /(\beta-\alpha)$, and the FDI mode with the complimentary probability, $(\delta-\alpha) /(\beta-\alpha)$. If firm $j$ opts for FDI, then its marginal cost does not include $t$. Consequently, firm $i$ 's expectation of firm $j$ 's marginal cost in market $i$ is equal to

$$
E_{i}\left(c_{j}^{f}\right)=\int_{\alpha}^{\delta} c \frac{1}{\beta-\alpha} d c+\int_{\delta}^{\beta}(c+t) \frac{1}{\beta-\alpha} d c=\frac{\beta+\alpha}{2}+\frac{t(\beta-\delta)}{\beta-\alpha} .
$$

By a similar reasoning, firm $i$ 's expectation of firm $j$ 's marginal cost of supplying market $j$ is equal to $E_{i}\left(c_{j}^{d}\right)=(\beta+\alpha) / 2$, and firm $j$ 's expectation of firm $i$ 's marginal cost of supplying market $j$ is equal to $E_{j}\left(c_{i}^{f}\right)=(\beta+\alpha) / 2+t(\beta-\delta) /(\beta-\alpha)$.

We now look at the optimal output decisions of the firms. To save on notation, we introduce the parameters $\Delta$ and $M$, defined as follows:

Definition $1 \Delta=2 A+(\beta+\alpha) / 2$, and $M=(\beta-\alpha)$.

Clearly, $M$ is the size of the support of the set of possible cost types. It is a measure of the degree of ex-ante heterogeneity. Each firm maximizes its expected profits, $\Pi_{X}(c)$ or $\Pi_{F D I}(c)$, when it serves the foreign market by exports or by FDI, respectively, taking into account the rival's expected costs. From the first-order conditions, the outputs supplied to country $i$ by the two firms are

$$
q_{i}^{d}=\frac{\Delta+2 t\left(\frac{\beta-\delta}{M}\right)-3 c_{i}}{6}, \quad q_{j}^{f}\left(m_{j}\right)=\frac{\Delta-t\left(\frac{\beta-\delta}{M}\right)-3 c_{j}^{f}\left(m_{j}\right)}{6}
$$

where the subscript denotes the location of a firm's headquarters; the superscript denotes the target market; and $m_{j}$ is the entry mode chosen by firm $j$ (i.e., $m_{j}$ is either exporting, $X$, or $F D I) .{ }^{13}$ Thus $c_{j}^{f}(X)=c_{j}+t$ (when firm $j$ exports to country $i$ ),

\footnotetext{
${ }^{13}$ For example, for firm $j$, the headquarters is in country $j$, and market $i$ is the "foreign" market. That
} 
and $c_{j}^{f}(F D I)=c_{j}$ (when firm $j$ undertakes FDI in country $i$ ). Similarly, the outputs supplied to market $j$ are

$$
q_{j}^{d}=\frac{\Delta+2 t\left(\frac{\beta-\delta}{M}\right)-3 c_{j}}{6}, \quad q_{i}^{f}\left(m_{i}\right)=\frac{\Delta-t\left(\frac{\beta-\delta}{M}\right)-3 c_{i}^{f}\left(m_{i}\right)}{6}
$$

where $c_{i}^{f}(X)=c_{i}+t$ and $c_{i}^{f}(F D I)=c_{i}$. In order to focus on the export-FDI trade-off, we assume that all outputs are positive throughout the paper. Otherwise, some types of firms would not produce at all, and this would not change our essential results except the exposition and expressions would be more cumbersome.

Given the optimal outputs in this Bayesian game, we can now compute the expected profits of the exporting firm, and of the firm undertaking FDI (after subtracting the fixed FDI cost $F$ ) given its cost type $c$ :

$$
\begin{aligned}
\Pi_{X}(c) & =\frac{\left(\Delta-t\left(\frac{\beta-\delta}{M}\right)-3(c+t)\right)^{2}}{36}, \\
\Pi_{F D I}(c) & =\frac{\left(\Delta-t\left(\frac{\beta-\delta}{M}\right)-3 c\right)^{2}}{36}-F .
\end{aligned}
$$

A firm of cost type $c$ prefers FDI over exporting if $\Pi_{F D I}(c)>\Pi_{X}(c)$. Therefore, given $\delta$, for a firm with marginal production cost $c$, FDI is the preferred mode of supply when the fixed FDI cost is sufficiently small such that

$$
F<\frac{t}{12}\left(2 \Delta-6 c-2 t\left(\frac{\beta-\delta}{M}\right)-3 t\right)
$$

As can be deduced from eq. (1a), a higher cost $c$ will reduce the expected profits under the FDI mode by more than those under the export mode: $\partial \Pi_{F D I} / \partial c<\partial \Pi_{X} / \partial c<0$. This confirms that if an interior solution exists, the lower-cost firms opt for FDI, while the higher-cost firms prefer exporting. Given $F$, we can determine the indifferent type is why we use the symbol $q_{j}^{f}$ in the above equation. 
$\delta$ by solving eq. (2): ${ }^{14}$

$$
F=\frac{t}{12}\left(2 \Delta-6 \delta-2 t\left(\frac{\beta-\delta}{M}\right)-3 t\right)
$$

We want to impose stability for our model: reducing fixed costs will, ceteris paribus, enable a wider range of firm types to undertake FDI. This is guaranteed by: ${ }^{15}$

Assumption $1 t<3 M$.

We can also scrutinize the corner solutions and demonstrate that the co-existence of exporters and multinationals is not a knife-edge case. All firms will prefer exporting over FDI when fixed FDI costs are sufficiently large. Let $F^{\prime}$ denote the threshold level of fixed FDI costs above which even the most efficient firm would prefer exporting to undertaking FDI. Thus, $F^{\prime}$ is set such that the lowest-cost firm is indifferent between trade and FDI $(c=\delta=\alpha)$ :

$$
F^{\prime}=\frac{t}{12}(2 \Delta-6 \alpha-5 t)
$$

We call $F^{\prime}$ the multinational-annihilating threshold of fixed costs under non-signaling. Similarly, we can show that all firms will prefer FDI over exporting when fixed FDI costs are sufficiently small. Let $F^{\prime \prime}$ denote the threshold level of fixed FDI costs below which even the least efficient firm would prefer undertaking FDI to exporting. Thus, $F^{\prime \prime}$

\footnotetext{
${ }^{14}$ As we will show below, for $\delta$ to belong to the interval $[\alpha, \beta]$, fixed costs $F$ must belong to some interval $\left[F_{L}, F_{H}\right]$.

${ }^{15}$ Given $F>0$ and $t>0$, we must find a fixed point, $\delta$, of the mapping $\Omega:[\alpha, \beta] \rightarrow[\alpha, \beta]$, where $\Omega(\delta) \equiv(1 / 6)[2 \Delta-3 t-2(t / M) \beta-12(F / t)+2(t / M) \delta]$. This fixed point changes as $F$ changes. The graph of the function $\Omega(\delta)$ shifts down as $F$ increases. This will result in a lower value for the fixed point iff the slope of the graph is less steep than the 45-degree line: iff $(t / 3 M)<1$. Imposing this condition amounts to requiring stability. For a more formal discussion of this stability requirement, see Appendix A.1.
} 
is set such that the highest-cost firm is indifferent between trade and FDI $(c=\delta=\beta)$ :

$$
F^{\prime \prime}=\frac{t}{12}(2 \Delta-6 \beta-3 t) .
$$

We call $F^{\prime \prime}$ the multinational-facilitating threshold of fixed costs under non-signaling.

By invoking Assumption 1, we can show that

$$
F^{\prime}-F^{\prime \prime}=t\left(\frac{3 M-t}{6}\right)>0
$$

This shows that there exists a non-degenerate interval of fixed costs, $\left[F^{\prime \prime}, F^{\prime}\right]$, and for any $F$ that lies in the interior of this interval, there is a corresponding threshold cost type, $\delta(F)$, where $\alpha<\delta(F)<\beta$, such that firms with marginal cost $c<\delta(F)$ will choose FDI and firms with marginal cost $c>\delta(F)$ will choose exporting.

What role does firm heterogeneity play for the co-existence of multinational firms and exporters? We can measure an increase in firm heterogeneity by a mean-preserving spread of the probability distribution $\Phi(c)$. We find that:

Proposition 1 (Mean-Preserving Spread I) An increase in heterogeneity at the firm level makes diversity of international business strategies more likely because it widens the range of fixed costs consistent with sorting. The measure of this widening is expressed by $\partial\left(F^{\prime}-F^{\prime \prime}\right) / \partial M=t / 2>0$.

Thus, firm heterogeneity is the key for the co-existence of exporters and multinationals. We can conclude that the same ranking of firms in terms of their productivity (as in heterogeneous firm models) in a model of incomplete information (such that more efficient firms undertake FDI, whereas less efficient firms self-select into exporting) and the greater the degree of ex-ante firm heterogeneity, the more likely we will observe a diversity of international business strategies. 


\section{$3 \quad$ FDI as a signal of productivity}

In the preceding section, we have assumed that FDI does not serve as a cost signal. In this section, we will explore how firms behave when FDI is an observable activity which precedes output decisions. For this purpose, we employ a two-stage Bayesian game. In the first stage, firms decide on the mode of supply: FDI or exporting. In the second stage, having observed the rival's mode of entry, each firm chooses its outputs for the two segmented markets. We look for a perfect Bayesian-Nash equilibrium in which FDI serves as a signal. After receiving the signal sent by the rival, firms will use the information to update their beliefs about the rival's marginal production costs, and in equilibrium this update must be consistent with the self-selection into exporting and FDI. In the first stage, however, the foreign market entry decision must be made without knowing the rival's decision.

We solve the problem backwards. First, we characterize the Stage 2 equilibrium outputs of the firms, given their knowledge of what have taken place in Stage 1. Let $\delta_{s}$ denote the type of the firm that is indifferent between exporting and FDI when firms make their entry mode decisions in Stage 1. At the beginning of Stage 2, there are four possible observations, which we call Outcomes 1 to 4 , and the details of which are elaborated in Appendix A.2.

Under Outcome 1, both firms opt for FDI. Then each firm uses the FDI signal to update its beliefs about the range of marginal production costs that the other firm operates in. In this case, they both signal that they are lower-cost firms, and this changes the nature of competition in the product market.

Under Outcome 2, firm $i$ undertakes FDI, but firm $j$ exports. In this case, firm $i$ signals that its marginal production costs are in the range $\left(\alpha, \delta_{s}\right)$, whereas firm $j$ signals that its marginal production costs are in the range $\left(\delta_{s}, \beta\right)$. Since firm $i$ has chosen to be multinational, firm $j$ 's expectation about firm $i$ 's marginal cost is the same for both 
markets. In contrast, firm $j$ has signaled that it is operating in the high-cost range, and since this makes firm $j$ an exporter, it will be expected to suffer a further disadvantage in firm $i$ 's home market due to trade costs.

The no-FDI signal sent by firm $j$ has two implications for firm $i$ : it learns that (i) the rival is relatively weak because it is in the high-cost range, and (ii) the rival is even weaker in firm $i$ 's home market, due to trade costs. It goes without saying that Outcome 2 would be most favorable for firm $i$.

Outcome 3 is simply a mirror image of Outcome 2: firm $i$ does not undertake FDI, but firm $j$ does. Outcome 4 occurs when both firms signal that their marginal production costs are in the high-cost range $\left(\delta_{s}, \beta\right)$.

We can then derive the expected profit (formed in Stage 1) of a firm whose realized marginal cost is $c$, conditional on its international business strategy. In forming this expectation, the firm knows that it faces two different possible actions by the other firm: (i) with probability $\left(\delta_{s}-\alpha\right) / M$, the rival firm's cost is sufficiently low that it chooses the FDI mode, and (ii) with the complementary probability, $\left(\beta-\delta_{s}\right) / M$, the rival firm's cost is sufficiently high that it prefers exporting. Appendix A.2 shows that FDI is the preferred mode of supply for a firm of type $c$, when fixed FDI costs are sufficiently small such that

$$
F_{s}<\frac{M\left(4 \Delta+\beta-2 \delta_{s}+\alpha\right)+4 t\left(4 \Delta+\beta-3 \delta_{s}+2 \alpha-8 t\right)-12 c(4 t+M)}{72} .
$$

As for firm behavior across different cost ranges, Appendix A.2 shows that, as $c$ increases, the exporting firm's expected total profits decrease by less than the decrease in the multinational's expected total profits. This confirms that if an interior solution exists, it will be the lower-cost firms that opt for FDI, whereas the higher-cost firms will prefer exporting. 
We can solve for the indifferent type $c=\delta_{s}$ :

$$
F_{s}=\frac{M\left(4 \Delta+\beta-2 \delta_{s}+\alpha\right)+4 t\left(4 \Delta+\beta-3 \delta_{s}+2 \alpha-8 t\right)-12 \delta_{s}(4 t+M)}{72} .
$$

We observe that $d \delta_{s} / d F_{s}<0$, irrespective of the size of $t$. Let us now look at the scope for the co-existence of multinationals and exporters. All firms prefer trade over FDI when fixed FDI costs are sufficiently large. Let $F_{s}^{\prime}$ denote the threshold level of fixed FDI costs above which even the most efficient firm would prefer exporting to undertaking FDI. Thus, $F_{s}^{\prime}$ is set such that the lowest-cost firm is indifferent between trade and FDI $\left(c=\delta_{s}=\alpha\right)$ :

$$
F_{s}^{\prime}=\frac{M(4 \Delta+M-12 \alpha)+4 t(4 \Delta+M-12 \alpha-8 t)}{72} .
$$

We call $F_{s}^{\prime}$ the multinational-annihilating threshold of fixed costs under signaling.

Similarly, we can show that all firms prefer FDI over exporting when fixed FDI costs are sufficiently small. Let $F_{s}^{\prime \prime}$ denote the threshold level of fixed FDI costs below which even the least efficient firm would prefer undertaking FDI to exporting. Thus, $F_{s}^{\prime \prime}$ is set such that the highest-cost firm is indifferent between trade and FDI $\left(c=\delta_{s}=\beta\right)$ :

$$
F_{s}^{\prime \prime}=\frac{M(4 \Delta-12 \beta-M)+8 t(2 \Delta-6 \beta-M-4 t)}{72} .
$$

We call $F_{s}^{\prime \prime}$ the multinational-facilitating threshold of fixed costs under signaling.

Clearly,

$$
F_{s}^{\prime}-F_{s}^{\prime \prime}=\frac{M(30 t+7 M)}{36}>0
$$

This shows that in the signaling case, there exists a non-degenerate interval of fixed costs, $\left[F_{s}^{\prime \prime}, F_{s}^{\prime}\right]$, and for any $F_{s}$ that lies in the interior of this interval, there is a corresponding threshold cost type, $\delta_{s}\left(F_{s}\right)$, where $\alpha<\delta_{s}\left(F_{s}\right)<\beta$, such that firms with marginal cost $c<\delta_{s}\left(F_{s}\right)$ will choose FDI and firms with marginal cost $c>\delta_{s}\left(F_{s}\right)$ will 
choose exporting. The following result shows that firm heterogeneity plays qualitatively a similar role as in the non-signaling case.

Proposition 2 (Mean-preserving spread II) An increase in heterogeneity at the firm level makes diversity of international business strategies more likely in the signaling case because it widens the range of fixed costs consistent with sorting. The measure of this widening in the signaling case is expressed by $\partial\left(F_{s}^{\prime}-F_{s}^{\prime \prime}\right) / \partial M=(15 t+7 M) / 18>0$.

Thus, we find that when FDI serves as a signal, the co-existence of exporters and multinationals remain possible within a range of fixed FDI costs, and this range widens with an increase in heterogeneity of cost types. In the next section, we will explore the main differences between the non-signaling and the signaling cases.

\section{The signaling effect of FDI}

The objective of this section is to determine how signaling alters the probability of FDI and the expected industry output. We compare the results of Section 2 (where FDI cannot be used as a signal) with the results of Section 3 (where FDI can serve as a signal). Let us start with the comparison of the threshold levels of fixed investment costs. We observe that

$$
\begin{aligned}
F_{s}^{\prime}-F^{\prime} & =\frac{M(4 \Delta-12 \alpha+4 t+M)}{72}+\frac{t(2 \Delta-6 \alpha-t)}{36}>0, \quad \text { (4a) } \\
F_{s}^{\prime \prime}-F^{\prime \prime} & =\frac{M(4 \Delta-12 \beta-8 t-M)}{72}+\frac{t(2 \Delta-6 \beta-7 t)}{36}>0, \text { (4b) } \\
\left(F_{s}^{\prime}-F_{s}^{\prime \prime}\right)-\left(F^{\prime}-F^{\prime \prime}\right) & =\frac{\left(7 M^{2}+6 t^{2}+12 M t\right)}{36}>0 .
\end{aligned}
$$

Eq. (4) shows that the signaling effect of FDI shifts both thresholds up, and leads to a wider range of fixed FDI costs in which we have the co-existence of exporters and 
multinationals. Figure 1 illustrates these result, and shows the indifferent types as a function of fixed costs.

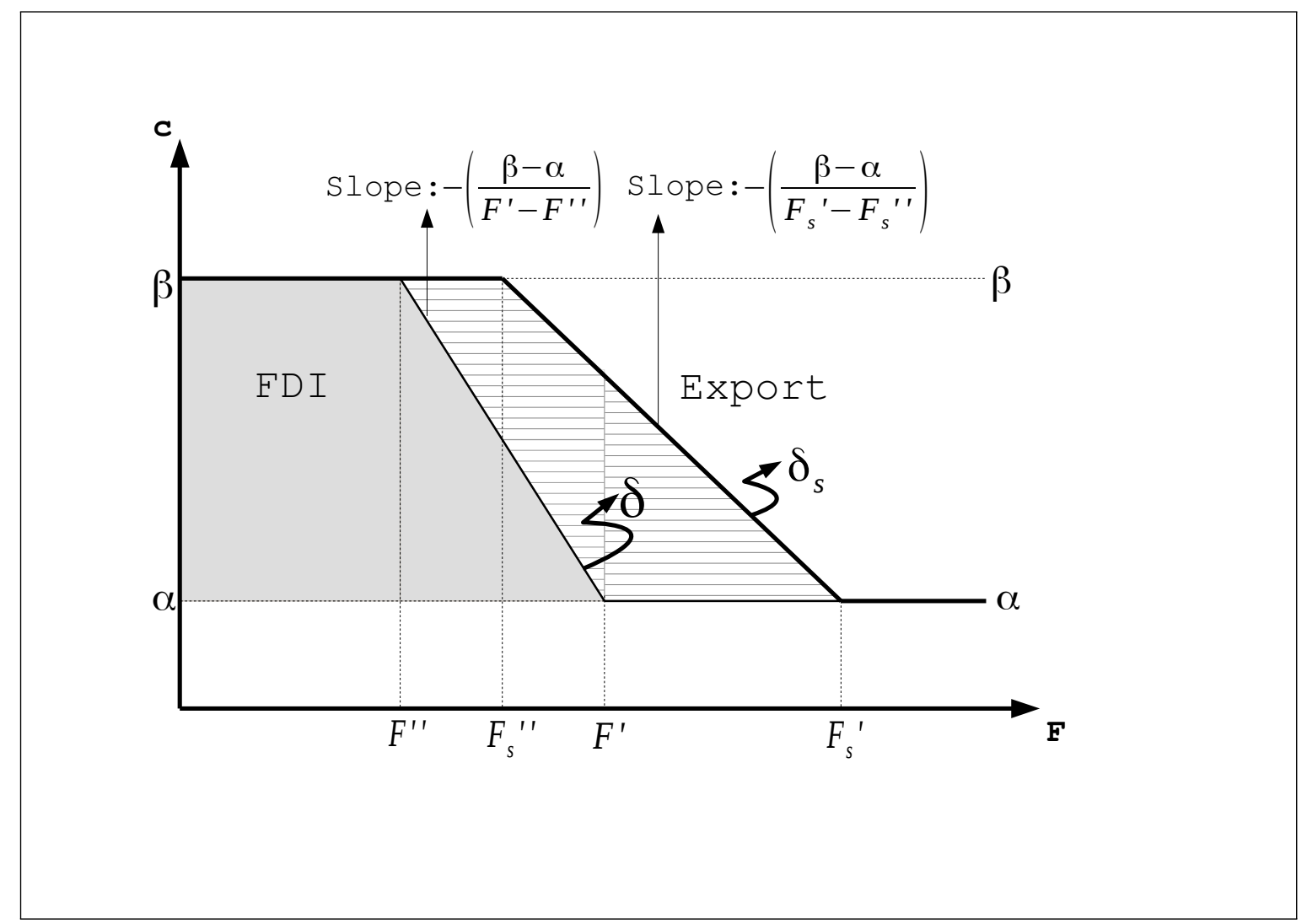

Figure 1: Indifferent types with and without signaling.

In Figure 1, fixed costs $(F)$ are on the horizontal axis, and the cost realizations of firms $(c \in[\alpha, \beta])$ are on the vertical axis. The indifferent types in the benchmark case (where FDI cannot be used as a signal) are represented by the fine black line $(\delta)$, below which firms opt for FDI, and above which firms export. When FDI can serve as a signal, the line representing the indifferent types is the thick black line $\left(\delta_{s}\right)$ : it is flatter than the fine black line $(\delta)$, as can be seen using eq. (4c). Furthermore it lies to the right of the fine black line $(\delta)$. For cost types above the line $\delta_{s}$, firms export. Below the line $\delta_{s}$, firms opt for FDI. The area with horizontal-hatching (between the two downward-sloping lines $\delta$ and $\delta_{s}$ ) clearly shows that the strategic signaling effect of 
FDI incentivizes some (less efficient) firms to switch their entry decision from exports to FDI.

As for the corner solutions, below $F_{s}^{\prime \prime}$ (in the signaling case) and $F^{\prime \prime}$ (in the benchmark case), all types opt for FDI; above $F_{s}^{\prime}$ (in the signaling case) and $F^{\prime}$ (in the benchmark case), all types prefer exporting, which leads to the horizontal lines in Figure 1. As is clear from Figure 1, and from the comparison of the threshold levels of fixed investment costs, the signaling effect of FDI makes FDI more likely, both in terms of the levels of fixed cost thresholds, and in terms of the size of the range of fixed investment costs. Furthermore, the change in the indifferent type with the critical fixed FDI costs is smaller in absolute terms in the case of signaling, as can easily be seen from differentiating and comparing eq. (2) and eq. (3). We summarize these findings in:

\section{Proposition 3 (Comparing the threshold fixed costs) (i) The probability of FDI} is larger if FDI can serve as a signal. (ii) With or without signaling, an increase in firm heterogeneity increases the range of fixed costs in which different types will choose different international business strategies, however the quantitative effect of an increase in firm heterogeneity is more pronounced in the signaling case.

Proof. The first part follows immediately from eq. (4a) and from Figure 1, whereas the second part follows from $\partial\left[\left(F_{s}^{\prime}-F_{s}^{\prime \prime}\right)-\left(F^{\prime}-F^{\prime \prime}\right)\right] / \partial M=(6 t+7 M) / 18>0$.

Since the indifferent type and the critical fixed FDI costs are inversely related, a direct implication of Proposition 3 is that more firms undertake FDI if FDI can serve as a signal because $\delta_{s} \geq \delta$ for any given fixed FDI costs (see Figure 1). This clear result in terms of the FDI probability indicates that consumers are likely to benefit from the signaling effect of FDI.

Let us now turn to the expected outputs. The details of the computation of the expected outputs are cumbersome, in particular for the case where FDI can serve as a signal of productivity (we must go through all four possible cases). These computations 
are reported briefly in Appendix 3. If FDI cannot be used as a signal of productivity, the computation of expected outputs is easier because the expected output of a firm in the local market does not depend on its international business strategy.

The details of the computations for both cases are included in Appendix A.3. Let $E\left[Q_{k}^{s}\right]$ (respectively, $E\left[Q_{k}\right]$ ) denotes the expected aggregate supply to market $k$ if FDI can (cannot) be a cost signal. The difference between the two expected aggregate supplies are

$$
\begin{aligned}
E\left[Q_{k}^{s}\right]-E\left[Q_{k}\right] & =\left(\frac{2 \Delta-3(\beta+\alpha)-\frac{2 t\left(\beta-\delta_{s}\right)}{M}}{6}\right)-\left(\frac{2 \Delta-3(\beta+\alpha)-\frac{2 t(\beta-\delta)}{M}}{6}\right) \\
& \left.=\frac{t\left(\delta_{s}-\delta\right)}{3 M} \geq 0, \quad \text { as } \delta_{s} \geq \delta, \text { for any given } F \text { (see Figure } 1\right) .
\end{aligned}
$$

This immediately leads to:

Proposition 4 Expected aggregate supply to each market is larger if FDI can serve as a signal of productivity.

Since the model is symmetric, this result applies also to the change in the expected world-wide (total) outputs of the firms. We are able to decompose the output changes into the changes in the two markets that the firms operate in. We find that the signaling effect of FDI makes each firm achieve a bigger market share in the foreign market (compared to the non-signaling case).

Proposition 5 The opportunity to use FDI as a signal of productivity reduces both firms' expected sales in their respective home markets by $t\left(\delta_{s}-\delta\right) / 3 M$, but increases their expected sales in the foreign markets by $2 t\left(\delta_{s}-\delta\right) / 3 M$.

Proposition 5 demonstrates the signaling effects of FDI. The FDI probability increases because not undertaking FDI is a bad signal, resulting not only in a reduced market share in the foreign market due to trade costs, but also in both the domestic and 
the foreign market due to signaling high marginal costs. Thus, firms are more willing to undertake FDI whenever FDI is a signal of productivity. A higher probability of FDI means that competition becomes more intense in both countries, and therefore firms are able to enlarge their market shares abroad, while accommodating foreign competition by reducing their market shares in their respective domestic markets. Can we say anything about the welfare effects of FDI when FDI is a signal of productivity? Consumers will always benefit from FDI as it will reduce the variable production costs. However, it is well known from duopoly models without firm heterogeneity that an FDI option can lead to a prisoners' dilemma for both firms: while each firm's total profits (from the two markets) would be larger if both firms were to choose exporting as the mode of supplying the foreign market, each firm has a unilateral incentive to become multinational. The profit decrease can even be larger than the consumer gain. ${ }^{16} \mathrm{We}$ cannot rule out that similar effects could be at work in our setup.

\section{Concluding remarks}

Our paper has shown that the capacity to signal productivity via FDI increases the incentive to undertake FDI. How do our results match empirical regularities? While we cannot offer direct empirical evidence on the signaling effect of FDI, there is indirect evidence supporting our hypothesis. For example, Helpman et al. (2004) find that the probability of FDI depends positively on both the level of $R \& D$ activities and a measure of industry heterogeneity. Similarly, Yeaple (2009) shows that the propensity of U.S. parent firms to invest in any given foreign market increases with parent firm size and with total factor productivity (TFP). Head and Ries (2003) and Tomiura (2007) report similar findings for Japanese manufacturing firms. ${ }^{17}$ Raff et al. (2012) also find that

\footnotetext{
${ }^{16}$ This result depends crucially on the assumption that market entry is not endogenous. With endogenous entry, the welfare effects of FDI are unambiguously positive (De Santis and Stähler, 2004).

${ }^{17}$ While controlling for productivity, for factor intensity, or for firm size, there is significant firm heterogeneity, which increases the probability of an FDI activity. Castellani and Giovannetti (2010),
} 
the probability of Japanese FDI depends positively on both the R\&D intensity and TFP. It is evident that both R\&D activities and TFP support FDI activities, though they do not seem to measure the same thing. In fact, the correlation between TFP and R\&D is only 0.217 in Raff et al. (2012), and the highest correlation is with firm size at a level of 0.312. By the same token, Head and Ries (2003), looking at publicly listed Japanese firms, show that firm size measures are not highly correlated with productivity measures (ranging from 0.05 to 0.27 ). It is, hence, not just a productivity draw from an exogenous distribution that determines firms' globalization, but also firms' R\&D efforts.

From this perspective, R\&D plays only one of its potential roles in our model: it generates uncertainty about a firm's marginal cost in the minds of its rivals, and this makes the firm more likely to opt for FDI as a signal, especially if the R\&D outcome is positive. Thus, while FDI is associated with high TFP (as in the standard heterogeneous firm literature) with or without $\mathrm{R} \& \mathrm{D}$, a firm is more likely to choose FDI for a given TFP in the presence of R\&D than in its absence. As the focus of our attention was the role of cost signaling via FDI, we have not endogenized the R\&D level as in the trade model of Long et al. (2011). Endogenizing R\&D would require to discuss whether the range of possible cost realizations monotonically increases with a firm's $R \& D$ level. If it does, we would expect not only more FDI due to the cost signaling effect but also more R\&D.

Another interesting extension of our paper could be to include some other possible avenues by which R\&D might promote FDI, irrespective of TFP. For example, R\&D may also improve the portability of a firm's technology, or may make a firm's product more appealing to foreign customers, especially through a quality upgrade or product differentiation). Furthermore, it would be interesting to explore the potential of cost

looking at Italian manufacturing firms, show that TFP premia for multinationals remain significant even after controlling for various firm characteristics, including R\&D intensity, and that firm heterogeneity seems to be not only in the intercept, but also in the slopes of the production function. 
signaling for different types of FDI where the selected FDI mode may serve as a signal as well. Our model is confined to greenfield FDI, but other FDI modes, for example forming a joint venture with a local partner or acquiring an existing firm may have different implications. We do not expect that our results will change as we know that also the FDI mode follows a productivity pattern: more productive firms prefer a greenfield investment over an acquisition and whole ownership over a joint venture (Raff et al., 2012). Therefore, the cost signaling effect should extend straightforwardly. 


\section{Appendix}

\section{A.1 Stability}

In the main text, we mentioned that Assumption 1 ensures stability. This argument can be made more formal. Since the two markets are segmented, we can focus on one market, say market $i$.

Suppose that firm $i$ guesses that firm $j$ has the following decision rule concerning its supply to market $i$.

Using a cost threshold $\delta \in[\alpha, \beta]$,

(i) if $c_{j}<\delta$, then firm $j$ undertakes FDI to supply the following quantity to market $i$ :

$$
q_{j}^{f}\left(c_{j} \mid c_{j}<\delta\right)=\frac{\Delta-t\left(\frac{\beta-\delta}{M}\right)-3 c_{j}}{6}
$$

(ii) if $c_{j}>\delta$, then firm $j$ exports the following quantity to market $i$ :

$$
q_{j}^{f}\left(c_{j} \mid c_{j}>\delta\right)=\frac{\Delta-t\left(\frac{\beta-\delta}{M}\right)-3\left(c_{j}+t\right)}{6} .
$$

Given $\delta^{e}$ that denotes the value of the cost threshold firm $i$ has guessed, firm $i$ 's expectation of foreign supply is, then,

$$
\begin{aligned}
E_{i}\left(q_{j}^{f}\right) & =\frac{\Delta-t\left(\frac{\beta-\delta^{e}}{M}\right)-3 c_{j}}{6}-\frac{3}{6} t \times \operatorname{Pr}\left[c_{j}>\delta^{e}\right] \\
& =\frac{\Delta-t\left(\frac{\beta-\delta^{e}}{M}\right)-3 c_{j}}{6}-\frac{3}{6} t\left(\frac{\beta-\delta^{e}}{M}\right) \\
& =\frac{1}{6}\left[2 A-4 t\left(\frac{\beta-\delta^{e}}{M}\right)-(\beta+\alpha)\right]
\end{aligned}
$$

Using this expectation, firm $i$, knowing its $\operatorname{cost} c_{i}$, will choose quantity $q_{i}^{d}$ to maximize its expected profit in the domestic market such that

$$
\max _{q_{i}^{d}}\left[A-E_{i}\left(q_{j}^{f}\right)-q_{i}^{d}-c_{i}\right] q_{i}^{d}
$$


which yields the first order condition

$$
q_{i}^{d}=\frac{1}{2}\left[A-E_{i}\left(q_{j}^{f}\right)-c_{i}\right]=\frac{\Delta+2 t\left(\frac{\beta-\delta^{e}}{M}\right)-3 c_{i}}{6} .
$$

Given this output strategy of firm $i$, which has $\operatorname{cost} c_{i}$ for market $i$, firm $j$, which does not know the value of $c_{i}$, calculates the expected value of firm $i$ 's supply, such that

$$
E_{j}\left(q_{i}^{d}\right)=\frac{\Delta+2 t\left(\frac{\beta-\delta^{e}}{M}\right)-3\left(\frac{\beta+\alpha}{2}\right)}{6}
$$

Firm $j$ must, then, decide how much to supply to market $i$ if it were to export, and how much to supply if it were to undertake FDI. Under the exporting mode, its profit is $\Pi_{X}\left(c_{j}\right)=\left[q_{j}^{f(X)}\left(c_{j}\right)\right]^{2}$, and under the FDI mode, it is $\Pi_{F D I}\left(c_{j}\right)=\left[q_{j}^{f(F D I)}\left(c_{j}\right)\right]^{2}-F$, where $q_{j}^{f(X)}\left(c_{j}\right)$ and $q_{j}^{f(F D I)}\left(c_{j}\right)$ are firm $j$ 's supply to market $i$ (conditional on its cost type $c_{j}$ ) under the exporting and the FDI mode, respectively, such that

$$
q_{j}^{f(X)}\left(c_{j}\right)=\frac{\Delta-t\left(\frac{\beta-\delta^{e}}{M}\right)-3\left(c_{j}+t\right)}{6}, \quad q_{j}^{f(F D I)}\left(c_{j}\right)=\frac{\Delta-t\left(\frac{\beta-\delta^{e}}{M}\right)-3 c_{j}}{6} .
$$

Clearly, $\Pi_{F D I}\left(c_{j}\right)>\Pi_{X}\left(c_{j}\right)$ iff $F<\left(2 \Delta-6 c_{j}-2 t\left(\beta-\delta^{e}\right) / M-3 t\right) t / 12$. The value of $c_{j}$ that satisfies the equation $F=\left(2 \Delta-6 c_{j}-2 t\left(\beta-\delta^{e}\right) / M-3 t\right) t / 12$, clearly, yields the optimal actual threshold to be used by firm $j$, denoted $\delta^{a}$, such that

$$
\delta^{a}=\frac{1}{6}\left[2 \Delta-2 t\left(\frac{\beta-\delta^{e}}{M}\right)-3 t-\frac{12 F}{t}\right] \equiv f\left(\delta^{e}\right) .
$$

Graphically, $\delta^{a}$ as a function of $\delta^{e}$ is an upward-sloping line with slope $2 t / M$. The intersection of this line and the 45-degree line determines the rational expectation equilibrium $\delta^{*}$ :

$$
\delta^{*}=\left(2 \Delta-\frac{2 t \beta}{M}-3 t-\frac{12 F}{t}\right) /\left(6-\frac{2 t}{M}\right) .
$$

We can think of an adjustment process that takes place out of equilibrium. Suppose at time $\tau$, we have $\delta^{a}(\tau)>\delta^{e}(\tau)$. In such a situation, we expect that $\delta^{e}$ would be adjusted upwards. Thus we postulate the following adjustment process, with $\gamma>0$,

$$
\dot{\delta}^{e}(\tau)=\gamma\left[\delta^{a}(\tau)-\delta^{e}(\tau)\right]=\frac{\gamma}{6}\left[2 \Delta-2 t\left(\frac{\beta}{M}\right)-3 t-\frac{12 F}{t}-\left(6-\frac{2 t}{M}\right) \delta^{e}(\tau)\right] .
$$

The solution of this linear differential equation converges to the steady state $\delta^{*}$ if and 
only if $6>2 t / M$ (i.e., iff Assumption 1 is satisfied).

Using the stability condition $6>2 t / M$, we find that an increase in $F$ will decrease $\delta^{*}$ : higher fixed FDI costs imply smaller ranges of firm types that prefer undertaking FDI to exporting.

Notice that $\delta^{*}=\alpha$ iff

$$
F=\frac{t(2 \Delta-6 \alpha-5 t)}{12} \equiv F^{\prime}
$$

and $\delta^{*}=\beta$ iff

$$
F=\frac{t(2 \Delta-6 \beta-3 t)}{12} \equiv F^{\prime \prime}
$$

where $F^{\prime}>F^{\prime \prime}$ under Assumption 1 .

Also notice that for any $F \in\left[F^{\prime \prime}, F^{\prime}\right]$, the function $f($.$) defined by eq. (A.1) maps [\alpha, \beta]$ into $[\alpha, \beta]$, and is a contraction mapping.

\section{A.2 Outputs and expected profits in case of signaling}

Outcome 1: Both firms have chosen FDI.

Conditional on this information, the expected marginal costs are given by

$$
E_{i}\left(c_{j}^{f}\right)=E_{i}\left(c_{j}^{d}\right)=E_{j}\left(c_{i}^{f}\right)=E_{j}\left(c_{i}^{d}\right)=\int_{\alpha}^{\delta_{s}} c \frac{d c}{\delta_{s}-\alpha}=\frac{\delta_{s}+\alpha}{2} .
$$

Accordingly, the quantities firms supply to market $i$ are given by

$$
q_{i}^{d}=\frac{\Delta-\left(\frac{\beta-\delta_{s}}{2}\right)-3 c_{i}}{6}, \quad q_{j}^{f}=\frac{\Delta-\left(\frac{\beta-\delta_{s}}{2}\right)-3 c_{j}}{6},
$$

where the subscripts and superscripts have the same meaning as in the preceding section. Due to symmetry, supplies to market $j$ are given by

$$
q_{i}^{f}=\frac{\Delta-\left(\frac{\beta-\delta_{s}}{2}\right)-3 c_{i}}{6}, \quad q_{j}^{d}=\frac{\Delta-\left(\frac{\beta-\delta_{s}}{2}\right)-3 c_{j}}{6} .
$$

Outcome 2: Firm $i$ has undertaken FDI, and firm $j$ has chosen to be an exporter. 
Conditional on this information, the expected marginal costs are given by

$$
\begin{aligned}
E_{j}\left(c_{i}^{d}\right)=E_{j}\left(c_{i}^{f}\right) & =\int_{\alpha}^{\delta_{s}} c \frac{d c}{\delta_{s}-\alpha}=\frac{\delta_{s}+\alpha}{2}, \\
E_{i}\left(c_{j}^{d}\right) & =\int_{\delta_{s}}^{\beta} c \frac{d c}{\beta-\delta_{s}}=\frac{\beta+\delta_{s}}{2}, \\
E_{i}\left(c_{j}^{f}\right) & =\int_{\delta_{s}}^{\beta}(c+t) \frac{d c}{\beta-\delta_{s}}=\frac{\beta+\delta_{s}}{2}+t .
\end{aligned}
$$

In this case, the quantities firms supply to market $i$ are given by

$$
q_{i}^{d}=\frac{\Delta+\left(\frac{\beta-\delta_{s}}{2}\right)+\left(\delta_{s}-\alpha\right)+2 t-3 c_{i}}{6}, \quad q_{j}^{f}=\frac{\Delta-\left(\frac{\delta_{s}-\alpha}{2}\right)-\left(\beta-\delta_{s}\right)-4 t-3 c_{j}}{6}
$$

and the quantities they supply to market $j$ are given by

$$
q_{i}^{f}=\frac{\Delta+\left(\frac{\beta-\delta_{s}}{2}\right)+\left(\delta_{s}-\alpha\right)-3 c_{i}}{6}, \quad q_{j}^{d}=\frac{\Delta-\left(\frac{\delta_{s}-\alpha}{2}\right)-\left(\beta-\delta_{s}\right)-3 c_{j}}{6} .
$$

Outcome 3: Firm $j$ has undertaken FDI, and firm $i$ has chosen to be an exporter.

This outcome is a mirror image of Outcome 3, so we do not report the equations here.

Outcome 4: Both firms have decided against FDI.

Conditional on this information, the expected marginal costs are given by

$$
\begin{aligned}
& E_{i}\left(c_{j}^{d}\right)=E_{j}\left(c_{i}^{d}\right)=\int_{\delta_{s}}^{\beta} c \frac{d c}{\beta-\delta_{s}}=\frac{\beta+\delta_{s}}{2}, \\
& E_{i}\left(c_{j}^{f}\right)=E_{j}\left(c_{i}^{f}\right)=\int_{\delta_{s}}^{\beta}(c+t) \frac{d c}{\beta-\delta_{s}}=\frac{\beta+\delta_{s}}{2}+t .
\end{aligned}
$$

Then their supplies of goods for market $i$ are given by

$$
q_{i}^{d}=\frac{\Delta+\left(\frac{\delta_{s}-\alpha}{2}\right)+2 t-3 c_{i}}{6}, \quad q_{j}^{f}=\frac{\Delta+\left(\frac{\delta_{s}-\alpha}{2}\right)-4 t-3 c_{j}}{6} .
$$

Similarly, for market $j$, their supplies are given by

$$
q_{i}^{f}=\frac{\Delta+\left(\frac{\delta_{s}-\alpha}{2}\right)-4 t-3 c_{i}}{6}, \quad q_{j}^{d}=\frac{\Delta+\left(\frac{\delta_{s}-\alpha}{2}\right)+2 t-3 c_{j}}{6} .
$$


Given the production levels above, we can compute firm i's expected total profits (without $\mathrm{R} \& \mathrm{D}$ costs) if it chooses the exporting mode, denoted by $\Pi_{X}$ :

$$
\begin{array}{r}
\Pi_{X}=\underbrace{\left(\frac{\delta_{s}-\alpha}{M}\right)}_{\operatorname{Pr}[\text { firm } j \rightarrow \text { FDI }]}(\underbrace{\frac{\left(\Delta+\left(\frac{\delta_{s}-\alpha}{2}\right)-M-3 c\right)^{2}}{36}}_{\text {Profits from country } i}+\underbrace{\frac{\left(\Delta+\left(\frac{\delta_{s}-\alpha}{2}\right)-M-4 t-3 c\right)^{2}}{36}}_{\text {Profits from country } j}) \\
+\underbrace{\left(\frac{\beta-\delta_{s}}{M}\right)}_{\operatorname{Pr}[\text { firm } j \rightarrow \mathrm{X}]}(\underbrace{\frac{\left(\Delta+\left(\frac{\delta_{s}-\alpha}{2}\right)+2 t-3 c\right)^{2}}{36}}_{\text {Profits from country } i}+\underbrace{\frac{\left(\Delta+\left(\frac{\delta_{s}-\alpha}{2}\right)-4 t-3 c\right)^{2}}{36}}_{\text {Profits from country } j})
\end{array}
$$

Similarly, we can compute firm $i$ 's expected total profits (without R\&D costs) if its mode of supply in country $j$ is FDI, denoted by $\Pi_{F D I}$ :

$$
\begin{array}{r}
\Pi_{F D I}=\underbrace{\left(\frac{\beta-\delta_{s}}{M}\right)}_{\operatorname{Pr}[\text { firm } j \rightarrow \mathrm{X}]}(\underbrace{\frac{\left(\Delta-\left(\frac{\beta-\delta_{s}}{2}\right)+M+2 t-3 c\right)^{2}}{36}}_{\text {Profits from country } i}+\underbrace{\frac{\left(\Delta-\left(\frac{\beta-\delta_{s}}{2}\right)+M-3 c\right)^{2}}{36}}_{\text {Profits from country } j}) \\
+\underbrace{\left(\frac{\delta_{s}-\alpha}{M}\right)}_{\operatorname{Pr}[\text { firm } j \rightarrow \text { FDI }]}(\underbrace{\frac{\left(\Delta-\left(\frac{\beta-\delta_{s}}{2}\right)-3 c\right)^{2}}{36}}_{\text {Profits from country } i}+\underbrace{\left.\frac{\left(\Delta-\left(\frac{\beta-\delta_{s}}{2}\right)-3 c\right)^{2}}{36}\right)}_{\text {Profits from country } j}-F_{s}(
\end{array}
$$

In eq. (A.3), $F_{s}$ denotes fixed FDI costs in the case FDI serves as a signal of productivity. Firm $i$ prefers FDI over exporting if $\Pi_{F D I}>\Pi_{X}$, leading to (3). Furtermore, we observe from eq. (A.2) and eq. (A.3) that, with an increase in $c$, the exporting firm's expected total profits decrease by less than the decrease in the multinational's expected total profits: $\partial \Pi_{F D I} / \partial c<\partial \Pi_{X} / \partial c<0$. 


\section{A.3 Expected aggregate outputs}

Expected aggregate outputs in country $k=\{i, j\}$ if FDI serves as a cost signal, denoted $E\left[Q_{k}^{s}\right]$, are given by

$$
\begin{aligned}
& \underbrace{\left(\frac{\delta_{s}-\alpha}{M}\right)\left(\frac{\beta-\delta_{s}}{M}\right)}_{\operatorname{Pr}[\text { firm } i \rightarrow \text { FDI, firm } j \rightarrow \mathrm{X}]}(\underbrace{\int_{\alpha}^{\delta_{s}}\left(\frac{\Delta-\frac{\left(\beta-\delta_{s}\right)}{2}+M+2 t-3 c}{6}\right) \frac{d c}{\delta_{s}-\alpha}}_{\text {Domestic (firm } i \text { 's) production }}+ \\
& \underbrace{\int_{\delta_{s}}^{\beta}\left(\frac{\Delta+\frac{\left(\delta_{s}-\alpha\right)}{2}-M-4 t-3 c}{6}\right) \frac{d c}{\beta-\delta_{s}}}_{\text {Foreign (firm } j \text { 's) production }})
\end{aligned}
$$

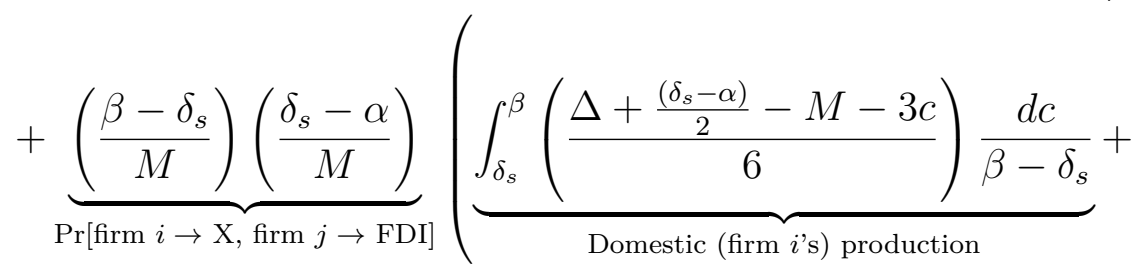

$$
\begin{aligned}
& \underbrace{\int_{\alpha}^{\delta_{s}}\left(\frac{\Delta-\frac{\left(\beta-\delta_{s}\right)}{2}+M-3 c}{6}\right) \frac{d c}{\delta_{s}-\alpha}}_{\text {Foreign (firm } j \text { 's) production }})+\underbrace{\left(\frac{\beta-\delta_{s}}{M}\right)^{2}}_{\operatorname{Pr}[\text { firm } i, j \rightarrow \mathrm{X}]} \\
& (\underbrace{\int_{\delta_{s}}^{\beta}\left(\frac{\Delta+\frac{\left(\delta_{s}-\alpha\right)}{2}+2 t-3 c}{6}\right) \frac{d c}{\beta-\delta_{s}}}_{\text {Domestic (firm } i \text { 's) production }}+\underbrace{\int_{\delta_{s}}^{\beta}\left(\frac{\Delta+\frac{\left(\delta_{s}-\alpha\right)}{2}-4 t-3 c}{\beta-\delta_{s}}\right) \frac{d c}{\beta}}_{\text {Foreign (firm } j^{\prime} \text { 's) production }}) \\
& +\underbrace{\left(\frac{\delta_{s}-\alpha}{M}\right)^{2}}_{\operatorname{Pr}[\text { firm } i, j \rightarrow \text { FDI }]}(\underbrace{2 \int_{\alpha}^{\delta_{s}}\left(\frac{\Delta-\frac{\left(\beta-\delta_{s}\right)}{2}-3 c}{6}\right) \frac{d c}{\delta_{s}-\alpha}}_{\text {Domestic (firm } i \text { 's) and foreign (firm } j \text { 's) production }}),
\end{aligned}
$$

where the expression $\operatorname{Pr}[$ firm $i \rightarrow \mathscr{S} \in\{$ FDI, X $\}$, firm $j \rightarrow \mathscr{S} \in\{$ FDI, X $\}]$ stands for the probability that one of the four outcomes discussed in Section 3 materializes in equilibrium which is determined by firms $i$ 's and firm $j$ 's self-selection into one of the two modes of foreign market entry (FDI or exporting). Note that the exporting strategy, here, is denoted by $X$.

Expected aggregate outputs in country $k=\{i, j\}$ if FDI cannot be a cost signal, 
denoted $E\left[Q_{k}\right]$, are given by

$$
\begin{array}{r}
\underbrace{\int_{\alpha}^{\delta}\left(\frac{\Delta-t\left(\frac{\beta-\delta}{M}\right)-3 c}{6}\right) \frac{d c}{M}+\int_{\delta}^{\beta}\left(\frac{\Delta-t\left(\frac{\beta-\delta}{M}\right)-3(c+t)}{6}\right) \frac{d c}{M}}_{\text {Foreign (firm } j \text { 's) production }} \\
+\underbrace{\int_{\alpha}^{\beta}\left(\frac{\Delta+2 t\left(\frac{\beta-\delta}{M}\right)-3 c}{6}\right) \frac{d c}{M}}_{\text {Domestic (firm } i \text { 's) production }} .
\end{array}
$$

Subtracting this expression from the preceding one leads to eq. (5).

\section{References}

[1] Antràs, P. 2003. Firms, contracts, and trade structure. Quarterly Journal of Economics 118, 1375-1418.

[2] Antràs, P., Yeaple, S.R. 2013. Multinational firms and the structure of international trade. NBER Working Paper 18775. Cambridge: National Bureau of Economic Research.

[3] Arnold, J.M., Hussinger, K. 2010. Exports versus FDI in German manufacturing: firm performance and participation in international markets. Review of International Economics 18, 595-606.

[4] Aw, B., Lee, Y. 2008. Firm heterogeneity and location choice for Taiwanese multinationals. Journal of International Economics 75, 67-179.

[5] Bagwell, K., Staiger, R.W. 2003. Informational aspects of foreign direct investment and the multinational firm. Japan and the World Economy 15, 1-20.

[6] Brander, J.A., Krugman, P. 1983. A "reciprocal dumping" model of international trade. Journal of International Economics 15, 313-323.

[7] Bulow, J.,Geanakoplos, J., Klemperer, P. 1985. Multimarket oligopoly: strategic substitutes and complements. Journal of Political Economy 93, 488-511.

[8] Castellani, D., Giovannetti, G. 2010. Productivity and the international firm: dissecting heterogeneity. Journal of Economic Policy Reform 13, 25-42.

[9] Castellani, D., Zanfei, A. 2007. Internationalisation, innovation and productivity: how do firms differ in Italy? World Economy 30, 156-176. 
[10] Collie, D., Hviid, M. 1993. Export subsidies as signals of competitiveness. Scandinavian Journal of Economics 95, 327-339.

[11] De Santis, R., Stähler, F. 2004. Endogenous market structures and the gains from foreign direct investment. Journal of International Economics 64, 545-565.

[12] García-Canal, E., Lópes Duarte, C., Rialp, J., Valdés, A. 2002. Accelerating international expansion through global alliances: a typology of cooperative strategies. Journal of World Business 37, 91-107.

[13] Girma, S., Görg, H., Strobl, E. 2004. Exports, international investment, and plant performance: evidence from a non-parametric test. Economics Letter 83, 317-324.

[14] Girma, S., Kneller, R., Pisu, M. 2005. Exports versus FDI: an empirical test. Review of World Economics 141, 193-218.

[15] Head, K., Ries, J. 2003. Heterogeneity and the FDI versus export decision of Japanese manufacturers. Journal of the Japanese and International Economies 17, 448-467.

[16] Helpman, E., Melitz, M.J., Yeaple, S.R. 2004. Export versus FDI with heterogeneous firms. American Economic Review 94, 300-316.

[17] Horstmann I.J., Markusen, J.R. 1992. Endogenous market structures in international trade (natura facit saltum). Journal of International Economics 32, 109129.

[18] Katayama, S., Miyagiwa, K. 2009. FDI as a signal of quality. Economics Letters 103, 127-130.

[19] Kimura, F., Kiyota, K. 2006. Exports, FDI, and productivity: dynamic evidence from Japanese firms. Review of World Economics 142, 695-719.

[20] Kreps, D., Scheinkman, J. 1983. Quantity precommitment and Bertrand competition yield Cournot outcomes. Bell Journal of Economics 14, 326-337.

[21] Long, N.V., Raff, H., Stähler, F. 2011. Innovation and trade with heterogeneous firms. Journal of International Economics 84, 149-159.

[22] Lópes Duarte, C.,García-Canal, E. 2004. The choice between joint ventures and acquisitions in foreign direct investment: the role of partial acquisitions and accrued experience. Thunderbird International Business Review 46, 39-58.

[23] Markusen, J.R. 1984. Multinationals, multi-plant economies, and the gains from trade. Journal of International Economics 16, 205-226.

[24] Markusen, J.R., Venables, A.J. 1998. Multinational firms and the new trade theory. Journal of International Economics 46, 183-203. 
[25] Markusen, J.R., Venables, A.J. 2000. The theory of endowment, intra-industry, and multinational trade. Journal of International Economics 52, 209-234.

[26] Mayer, T., Ottaviano, G.I.P. 2008. The happy few: the internationalisation of European firms. Intereconomics: Review of European Economic Policy 43, 135148.

[27] Melitz, M.J. 2003. The impact of trade on intra-industry reallocations and aggregate industry productivity. Econometrica 71, 1695-1725.

[28] Moner-Colonques, R., Orts, V., Sempere-Monerris, J.J. 2007. Asymmetric demand information and foreign direct investment. Scandinavian Journal of Economics 109, 93-106.

[29] Mrázová, M., Neary, P.J. 2013. Selection effects with heterogeneous firms. Mimeo.

[30] Nastasi, A., Reverberi, P. 2007. Foreign market entry strategies under asymmetric information. Review of International Economics 15, 758-781.

[31] Navaretti, G.B., Venables, A.J. 2004. Multinational Firms in the World Economy. Princeton: Princeton University Press.

[32] Nocke, V., Yeaple, S. 2007. Cross-border mergers and acquisitions vs. greenfield foreign direct investment: the role of firm heterogeneity. Journal of International Economics 72, 336-365.

[33] Raff, H., Ryan M., Stähler, F. 2012. Firm productivity and the foreign-market entry decision. Journal of Economics \&6 Management Strategy 21, 849-871.

[34] Shen, J., Reuer, J.R. 2005. Adverse selection in acquisitions of small manufacturing firms: a comparison of private and public targets. Small Business Economics 24, 393-407.

[35] Tomiura, E. 2007. Foreign outsourcing, exporting, and FDI: a productivity comparison at the firm level. Journal of International Economics 72, 113-127.

[36] Vives, X. 2002. Private information, strategic behavior, and efficiency in Cournot markets. Rand Journal of Economics 33, 361-376.

[37] Wagner, J. 2006. Exports, foreign direct investment, and productivity: evidence from German firm level data. Applied Economics Letters 13, 347-349.

[38] Yeaple, S.R. 2009. Firm heterogeneity and the structure of U.S. multinational activity. Journal of International Economics 78, 206-215. 